\title{
Features, Trends and Characteristics of Remote Access Laboratory Management Systems
}

\author{
http://dx.doi.org/10.3991/ijoe.v10i2.3221 \\ Ananda Maiti, Andrew D. Maxwell and Alexander A. Kist \\ University of Southern Queensland, Toowoomba, QLD, Australia
}

\begin{abstract}
Remote Access Laboratories are being used around the globe to enable engineering students to practice practical skills and enhance their knowledge through handson experimentation. These facilities also increase access by allowing users to undertake experiments anywhere anytime thus offering more flexibility and mobility. Several RAL systems have successfully met these goals. However, the role of experiment designers has rarely being explored or expanded since the conception of RAL systems. Experiments are designed and put on internet by a small group of experts in their respective fields. While these systems have been successful for universities where experts and suitable environment are available, they have rarely been used in the schools; and Science, Technology, Engineering and Mathematics (STEM) education. As the pedagogical design is now seen as a critical development in the instigation of new experiments, any RAL for STEM education initiative must address pedagogical considerations from the onset. In this paper, the common attributes of the leading RAL systems are discussed and the basic denominators are identified to establish common feature that are widely implemented in RAL systems. Limitations for their use in STEM education are analysed. The paper concludes that RAL architectures need to incorporate new aspects such as the peer-to-peer access paradigm in order to become viable STEM-based education tools.
\end{abstract}

Index Terms - remote laboratories; e-learning; computer networks; web technologies; instrumentation

\section{INTRODUCTION}

The information and communication technology today has enabled fast and rich ways of exchanging information between people from different domains with a variety of applications. One such application is the Remote Access Laboratories (RAL) or Remote Laboratories, which are web-based interactive systems that gives students the ability to control and observe the characteristics and processes of remote equipment through the internet [1-5]. Teaching Science, Technology, Engineering and Mathematics at schools (known as STEM) is seen as an effective way of growing interest in science related fields [6]. Such education needs practical hands on experience in combination with theoretical knowledge of STEM concepts. Practical experience is acquired by physically building, observing and recording facts from different equipment setups and environments.

RALs can provide access to resources which are otherwise inaccessible to users. Typically all that is required is a web browser and an internet connection to enable rich educational experiences. Traditionally remote laboratories have been deployed by institutions for their own student cohorts or community members associated with the university. A 2010 survey advocated 'Virtual \& Remote Labs' as the top choice for enhancing engineering education [4]. A number of collaborative projects have integrated experiments under a common infrastructure. Aims of these efforts typically include simple access by students and support of collaboration among students [78]. Research has mainly focused on integrating RAL experiments into higher education, including undergraduate courses [9-11]. Typically, because of large number students, limited hardware and defined sets of experimental setups.

The aim of this paper is to examine current trends and features of RAL systems and initiatives; and to contrast those with requirements and constraints of a K12 curriculum oriented STEM education. To do this, a model is created of what key components comprise a "good" RAL system and what are common characteristics of all RAL systems. It is observed that various components of RAL are implemented in different ways; however, common properties are retained and similar services are exposed. The general features of remote laboratories are compared to establish the common standards being followed for creating RALs, and how their designers use them for teaching. This is found to be as too complex and designer oriented i.e. specialized to particular domains of laboratory experience. This is stated as a reason for a relatively slow adoption of RAL as a regular tool, especially within K12 education. This paper extends [12] by analysing RAL system features in the context of STEM education.

In Section 2 expected features of remote laboratories are outlined in the context of laboratory learning in engineering followed by a program logic model to explain the origin and development of remote laboratory architectures. In Section 3, common characteristics are formulated followed by detailed examination of different RALs systems in Section 4. Technical criteria and features are evaluated. Common features and tends are discussed in Section 5. Limitations and drawbacks of RAL systems in the context of their adoption for K12 education; and potential solutions are presented in Section 6 .

\section{RESEARCH METHODOLOGY}

\section{A. RAL requirements for $K 12$ education}

STEM education in schools is very important for students to develop interests in further studies in these fields. A major problem of practical STEM education is that expert expertise is required to develop and operate 
(remotely accessible) experiments in home or schools environments. One of the main challenges of STEM education is to finding new and creative ways to express ideas with aids of physical means and understand each aspect of the entity being studied. STEM based education also encourages the use of enquiry based learning which requires hands-on experience, including building of the experimental setup and collaborating between students $[13,6]$. Existing RAL architectures fall short in these criteria as discussed in the next sections.

\section{B. Research Framework}

Laboratory and practical activities form an integral part of Engineering Education. At an ABET Colloquy [14], a set of thirteen common learning outcomes for engineering laboratory activities were identified. Traditionally practice classes are taught face-to-face; however, Remote Access Laboratories have been widely discussed as potential alternatives for online delivery. Drivers to develop remote laboratories differ and include the ability to share hardware between physical locations within and between and institutions e.g. remotely controlled robots [15] and control laboratories [16], economic benefits [17] and access for distance education students [18]. RAL literature largely focuses on technical system implementation details; questions regarding learning outcomes and pedagogy are often not addressed.

Another common deficiency with laboratory work in science and engineering curricular is that objectives for practical activities are not explicitly addressed [14]. This makes it difficult to judge the educational effectiveness of RAL activities. In particular since "the pedagogical effectiveness of any educational activity is judged by whether or not the intended learning outcomes are achieved" [19]. As this paper focuses on the system design, it addresses this question by considering the factors that lead to the creation of a RAL, as well as the sub components that make up the final system with respect to both technical requirements, as well as educational and pedagogy considerations.

\section{Research Methodology}

To evaluate and compare different RAL systems and establish whether individual approaches have major advantages over others, a Program Logic method [20] is used. This method maps inputs, activities, outputs, outcomes and impacts. As this paper addresses the overall system design, the evaluation is limited only to aspects that are relevant in this context. Fig. 1 summarizes the program logic used for a generic RAL system.

The situation is depicted on the left-hand side and includes the technical advances that have been possible with the developments in computing and communication, i.e. the Internet. This also includes generally underutilized laboratory spaces and student access to practical experiments. In the context of distance education, for example, this issue is dominant. The next box depicts the inputs. Most RAL systems have originated from academics with a keen interest in technology. Additionally, funding, institutional support and other resources play a vital role.

Another consideration is that of isolated development, or development based on other published system designs. Outputs include the actually developed RAL system that solve the access problem and the experiment or 'rig' design. Students using the systems and dissemination of novel results are also important outputs. The impact of these activities is arrived at by improved access for students (temporal and geographical) and collaborative opportunities; improved pedagogies and wider use; as well as changes to learning and teaching paradigms. To complete the methodology, the following aspects of these systems where evaluated: Initial Problem, Pedagogy, Web Interface Design, Innovative Features, Users, Scheduling, Programming Languages, impact and major academic fields.

\section{REMOTE LABORATORY - BASIC COMPONENTS}

Within a RAL system there are traditionally two nodes, the server and the client (see Fig. 2). The users' side consists of the students engaging and learning from use of the experiment, with the server side providing the experiment 'rig', as well as the experiment designers responsible for designing, creating and maintaining the experiment designed to allow experiential learning of concepts and learning materials. RLMS are responsible for arbitrated interaction between all components and interfaces in the system. Typically RLMSs have certain common components:

- Scheduling

- Rig operations

- Transport layer

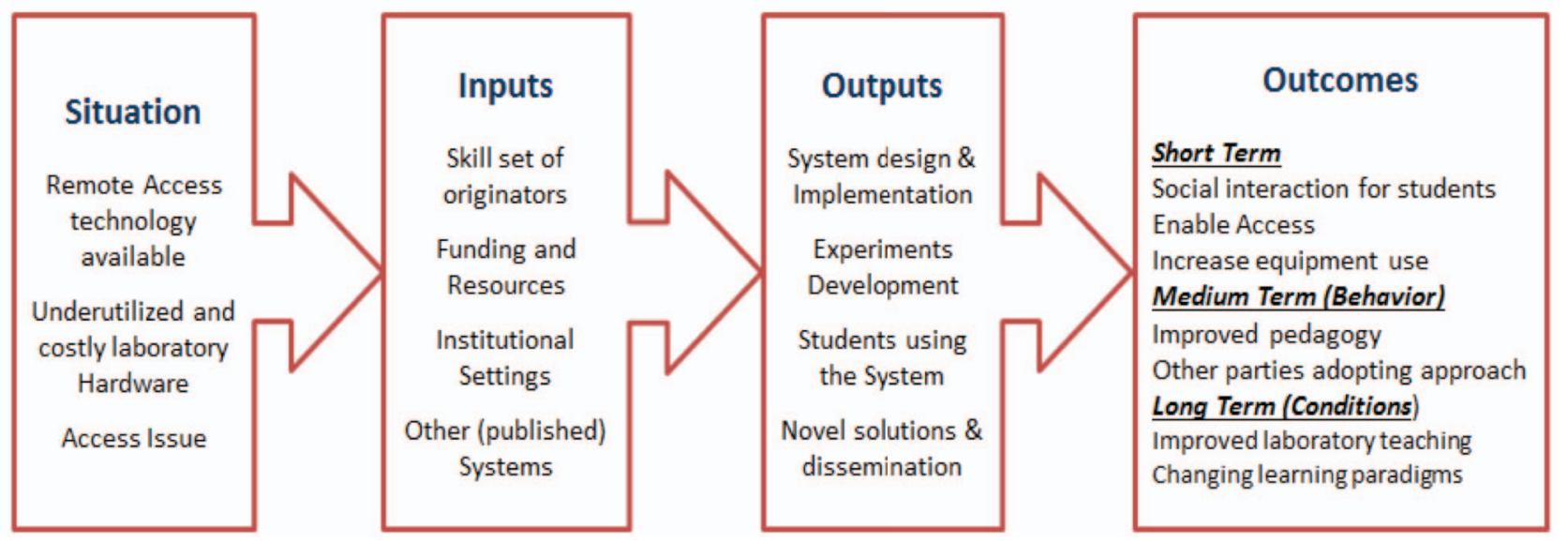

Fig 1. Program Logic for RAL evaluation. 
- Multimedia tools/data about experiments

- Experiment user interface

- Accepting and processing user requests

- Storing and maintaining user details

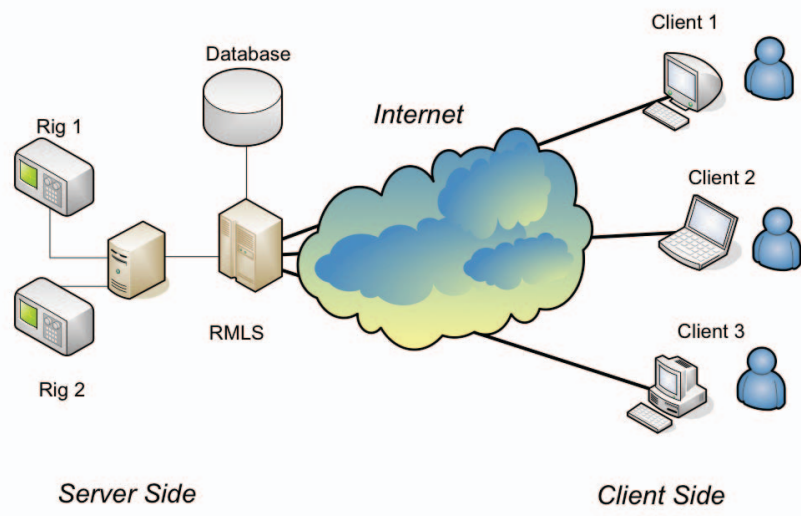

Figure 2. Typical RLMS System Architecture.

\section{STUDY OF DIFFERENT RAL SYSTEMS}

Some of the largest and most widely used RLMSs are chosen for comparison because these have been developed and used for several years namely iLab [1, 11], SAHARA [7] and VISIR [21].

\section{A. System architecture}

The iLab has a three layered architecture called the iLab Shared Architecture (ISA). Users connect with a service broker server, which in turn makes a connection with the actual laboratory server. The system architecture is heavily dependent on web services [1]. iLab has also been used to implement extensions such as iLab-MIT-Africa [22] in African nations and some universities in Australia. Experiments in iLab have been categorized into three different delivery methods: batched, interactive and sensor. iLab is based on the Microsoft platforms including Visual C\#, .NET framework tools and Microsoft SQL Server. This makes the system very platform dependent, consequently it is difficult to implement on open source platforms. Recent attempts are being made to reimplement the ISA in Java in an attempt to make it platform independent [23].

SAHARA originally followed a client-server architecture, where all experiments were hosted at the UTS laboratories, and accessed upon request by remote users. In this design, the lists of experiments are stored by the central server, which is also responsible for other operational aspects including running the RAL, scheduling, and operating the rig. Recent developments in SAHARA have moved towards grid architecture, but mostly within partner institutions. VISIR implementations also follow client server architecture, where all the experiment lists are stored in centralized databases along with user details, and connection to the same server is used for booking and operating the experiment. Both iLab and VISIR use LabVIEW as the main platform and language to write programs to operate instruments.

\section{B. Experiment scheduling}

iLab follows a queuing method for scheduling experiments with users. All requests are placed in a queue and processed successively one after another. Users of VISIR follow a time-slot booking method by assigning a particular time period in the future to a particular student [9]. Only the student allocated that time-slot can control the instruments and measure data. The SAHARA software release is available freely with the following modules [7]:

- Scheduling scheme - Both Queuing and Reservation Systems

\section{- $\quad$ Rig Management and Alarming}

This can be used by developers to implement their own laboratory management systems although it is still useful only for people who already have a laboratory rather than individuals or small groups of users. Teachers can also make requests to the laboratory manager for a rig, upon which it is shared with the interested group.

\section{Deploying new experiments}

In all cases new experiments are chosen by the administrators based on the university curriculum and educational needs according to the subjects being taught. The instruments used are typically of high cost featuring complex functions. Due to the nature of the experiments, these systems have to be developed within the laboratories of participating universities. The experiment configurations are generally composed of several experimental apparatus operated by a high level language, and typically involve a PC computer based controller. The user interface for the remote laboratory is also typically created by the laboratory staff. The scheduling aspect is easy to implement for instance as in the SAHARA software. These features allow developers to implement their own laboratory management systems.

VISIR, which provides workbench environment and set of experiments, is flexible but still limited to the number of experiments that can be performed with the given restricted component set [24]. In this instance there is no scope of deploying any new module extensions, except for where VISIR developers extend the features and components of the hardware.

\section{Nature of experiments}

Within iLab the experiments are varied in nature and maintained by different laboratories at MIT with different experiment focus. The micro-electronics laboratory for instance is the most used experiment. In addition to this, there are other laboratories for control theory, circuits' laboratory, micro-electronics and physics. All laboratories are built with a key focus on the required laboratory experience for undergraduate and graduate courses. For Labshare, the experiments are also from varied fields such as physics and electronics. Some of the typical experiments available as of now are:

- Beam Deflection

- Fluid Mechanics

- FPGA Experiment

- Microcontroller design

VISIR is restricted for use with the analog electronics basic experiments [25]. The UI for VISIR features considerable flexibility and intelligence. The users can assemble and measure currents, voltage and other properties of serial and parallel circuits. The environment can detect and immediately inform users making incorrect connections such as short circuits. This increases the students understanding about what can go wrong while 
designing a circuit. Although VISIR provides more definite sets of experiments, it is restricted to core electrical and electronics education for undergraduate students [26]. VISIR has been used by several universities such as Carinthia Technical Institute Austria, UNED Madrid Spain, Univ. of Duesto Bilbao Spain and ISEP for their undergraduate curriculum.

\section{E. Notable Features of WebLab@Duesto}

Univ. of Duesto, Bilbao Spain developed the WebLabDeusto remote laboratories [3-4] in the early 2000s. This system uses the client-server mechanism, utilizing mostly time reservation with priority queuing based scheduling [27], although the nature of scheduling can change if connecting to other systems. Within this particular system, there is a wide variety of experiments ranging from basics of physics to FPGA [28], although the main focus is on electronics and electrical experiments. But like all RLMSs, new experiments are designed by laboratory experts based on educational needs of their undergraduate students.

The most notable features of WebLab are

i. Integration with other RLMSs such as VISIR [29] to use their experiments

ii. 3D user interface in second-life called the 'SecondLab' [30]. SecondLab merges all the RAL components and allows students to program a micro-bot from Second Life with visual feedback. However the experiments portal is highly dependent on the type of experiment being implemented.

\section{F. USQ RAL}

The University of Southern Queensland is distance education provider and in engineering typically $75 \%$ are external students who are located off-campus. RAL has become a viable option to improve the learning experience of external students. In most cases the RAL activities are undertaken in addition to face-to-face residential school, in some cases students work remotely instead of visiting the university periodically [31]. Remote access laboratories have been successfully used at the USQ in teaching fields from education [32, 33], nursing [34, 35], and geographic information systems [36] to hydraulics and power engineering. This has been possible through extending the traditional definition of remote laboratories from controlling hardware remotely to conceptual space of conducting experiments remotely [18].

The experiments are all hosted at the university site and have been designed by academics. This RAL system uses the remote desktop sharing as an experiment access paradigm. Sessions are authenticated via a booking system that integrates with the institutional LMS. It allows users to view the experiments and the interface by directly transmitting the desktop image from the university servers to the user's desktop. A lot of different equipment can be run out-of-the-box using this approach making it very easy to implement any experiment quickly without much expertise. This system follows a time-scheduling approach and uses native programs of the rigs to operate them.

\section{G. Other RAL Examples}

In 2011, the project 'LiLa' (Library of Labs) was

TABLE I

COMPARISON BETWEEN LABS

\begin{tabular}{|c|c|c|c|c|c|c|}
\hline & Netlab (UniSA) & $i L a b, M I T, U S A$ & VISIR, Sweden & $\begin{array}{l}\text { Labshare, } \\
\text { Australia }\end{array}$ & $\begin{array}{c}\text { WebLab } \\
\text { Duesto }\end{array}$ & $U S Q R A L$ \\
\hline Initial Problem & Accessibility & Accessibility & $\begin{array}{l}\text { Accessibility, } \\
\text { User Experience }\end{array}$ & Resource Sharing & Accessibility & $\begin{array}{c}\text { Distant } \\
\text { Education }\end{array}$ \\
\hline Pedagogy & $\begin{array}{l}\text { Investigated } \\
\text { Implemented }\end{array}$ & Investigated & Investigated & Investigated & - & Investigated \\
\hline $\begin{array}{c}\text { Web Interface } \\
\text { Design }\end{array}$ & $\begin{array}{l}\text { Similar to } \\
\text { classroom }\end{array}$ & $\begin{array}{l}\text { Mimic Interface \& } \\
\text { LabVIEW interface }\end{array}$ & $\begin{array}{l}\text { Similar to } \\
\text { classroom }\end{array}$ & $\begin{array}{c}\text { LabVIEW } \\
\text { interface, Mimic } \\
\text { Interface }\end{array}$ & $\begin{array}{l}\text { Mimic } \\
\text { Interface }\end{array}$ & $\begin{array}{l}\text { Desktop } \\
\text { Sharing }\end{array}$ \\
\hline $\begin{array}{l}\text { Notable } \\
\text { System } \\
\text { Features }\end{array}$ & $\begin{array}{l}\text { Co-operative } \\
\text { Activities }\end{array}$ & $\begin{array}{l}\text { iLab Shared Architecture } \\
\text { (ISA) \& service broker }\end{array}$ & $\begin{array}{c}\text { Flexible } \\
\text { electronics } \\
\text { circuit hardware }\end{array}$ & Collaboration & 3D Interaction & $\begin{array}{c}\text { Easy Out-of- } \\
\text { box } \\
\text { implementation }\end{array}$ \\
\hline Users & Undergraduate & Undergraduate & Undergraduate & Undergraduate & Undergraduate & Undergraduate \\
\hline Scheduling & Time-Booking & $\begin{array}{l}\text { Queuing (batched expts.) } \\
\text { \& Time-Booking } \\
\text { (interactive expts.) }\end{array}$ & $\begin{array}{l}\text { Time- } \\
\text { Reservation }\end{array}$ & $\begin{array}{l}\text { Time- Booking } \\
\text { Queuing Hybrid }\end{array}$ & $\begin{array}{l}\text { Time- } \\
\text { Reservation } \\
\text { (with priority } \\
\text { Queuing) }\end{array}$ & Time Booking \\
\hline $\begin{array}{l}\text { Programming } \\
\text { Language }(s)- \\
\text { Rigs }\end{array}$ & JAVA & LabVIEW & LabVIEW & LabVIEW & - & Native \\
\hline $\begin{array}{c}\text { Programming } \\
\text { Language(s) - } \\
\text { UI }\end{array}$ & JAVA & JAVA & Flash & $\begin{array}{l}\text { LabVIEW } \\
\text { Interface }\end{array}$ & HTML, Flash & Native \\
\hline $\begin{array}{l}\text { Major } \\
\text { Academic } \\
\text { Fields }\end{array}$ & $\begin{array}{l}\text { Electrical } \\
\text { Circuits }\end{array}$ & $\begin{array}{l}\text { Control theory, circuits } \\
\text { laboratory, micro- } \\
\text { electronics and physics }\end{array}$ & $\begin{array}{l}\text { Analogue } \\
\text { electronics }\end{array}$ & $\begin{array}{l}\text { Physics, } \\
\text { Electronics, } \\
\text { Electrical }\end{array}$ & $\begin{array}{l}\text { Physics, } \\
\text { Electronics } \\
\text { (FPGA) }\end{array}$ & $\begin{array}{l}\text { Hydraulics, } \\
\text { Nursing, } \\
\text { Geographic } \\
\text { information } \\
\text { system, } \\
\text { Networking }\end{array}$ \\
\hline Impact & $\begin{array}{c}\text { Initiated } \\
\text { Co-operative } \\
\text { Experiments }\end{array}$ & $\begin{array}{l}\text { Used in Africa and } \\
\text { Australia }\end{array}$ & $\begin{array}{l}\text { Collaboration } \\
\text { with others }\end{array}$ & $\begin{array}{l}\text { Used by school } \\
\text { students }\end{array}$ & $\begin{array}{l}\text { Collaboration } \\
\text { with others }\end{array}$ & $\begin{array}{l}\text { Collaboration } \\
\text { with non- } \\
\text { technical } \\
\text { disciplines }\end{array}$ \\
\hline
\end{tabular}


started as a collaborative venture between several RAL installations throughout Europe. Many virtual and remote experiments were shared by partner institutions through a Learning Management Systems (LMS) and the 'LiLa Internet Portal'. The learning aspects of LiLa were managed using SCORM, a learning object creation and management tool [8]. Actual operating and related costs of the laboratories however were still borne by the participating universities.

REXLab (Brazil) was created in Brazil. It has RAL experiments that could be accessed via the mobile devices. An experimental 3D Augmented Reality activity using LabVIEW has been reported [37]. RemoteElectlab [38] was developed at FEUP, Porto, Portugal targeting Mechanical, Physics Electronics and Meteorological experiments. eMersion and SMARTLAB have been used at EPFL, Switzerland which uses the 'Graaasp' social media platform [4]. This also is for higher education students in the fields of Control Theory, Physics, etc.

\section{FEATURES AND TRENDS OF RLMS}

To establish the difference between the systems the following criteria were examined:

\section{A. Why were these Laboratories rolled out?}

Most laboratories have their origins addressing problem of inaccessibility of equipment (i.e. more students and limited instruments) including iLab, Netlab (UniSA) and WebLab-Duesto. The UTS laboratories were developed to offer more expensive and hence higher performance instruments than the ones being used in the regular laboratories. Later Labshare and LiLa were initiated to share resources among different institutions in Australia and Europe. VISIR was initiated to provide knowledge of the difference between simulated data and real experimental data on a computer.

\section{B. Advanced and Innovative Applications}

As with the original concepts of RAL, each system started by providing access to the instruments over the internet, i.e. that users be able to access the instruments from their computers. Later, several innovative steps were introduced that could be used to enhance the student learning such as:

$i$. Virtual 3D Environment: Several RAL systems have used 3D interactive and immersive environments to simulate the real world experience in the virtual world. The RemoteElectlab (Porto) has preseted a case study for accessing a digital multi-meter through a 3D immersive environment [38]. iLab have created the TEALsim system to provide interactive physics experiments on magnetism [39]. REXLab has implemented a young's modulus experiment in a 3D virtual laboratory environment [37]. WebLab also introduced the most significant of these 3D systems, SecondLab, which is based on the SecondLife virtual world environment [30].

ii. Co-operation between students in experiments: Operating experiments via the internet also allows for co-operation and collaboration between different students interacting, watching or lurking within the same experiment simultaneously. All of the 3D environments stated above already allow multiple users to access the experiment at a given time. In these instances, the users are represented by their avatars. Netlab was one of the earliest systems to implement interstudent collaboration [40]. Should it be desired, a multiuser interactive collaborative environment is required to allow concurrent users to have control over the entire experiment simultaneously.

iii. Dynamic Components Assembly: VISIR created a relay based dynamic circuit assembly system to allow students to build and test circuits during sessions by using micro controllers through a computer server. The Netlab system also follows a similar approach to connect several instruments together dynamically to form the experiment. Other systems have implemented this technology [41].

iv. Reconfigurable Laboratory Kit: One general drawback of RAL systems are they provide only a static set of experiemtns and the users never actually set them up. There have been some efforts to create low-cost reconfigurable laboratory devices that may be used by individuals to create and test experiemtns. An adaptable model of remote laboratory platform that can be easily re-assembles/configured for electronics laboratories allows large number of reconfigurations has been reported [42]. The WebLab@Duesto has also created one such device.

v. Scheduling schemes: Remote laboratories pose a very unique scheduling prolem. It's a major technical difference in implementatio of on-site and the remote laboratories. All RLMS have implemented some innovative solution to it [43] with two fundamental strategies used - queuing and time-slotted booking [27]. In some RAL systems where only brief interactions between users and rigs are required, a reservation mechanism is used where users are presented with links to the experiment on a firstcome-first-serve basis.

vi. Lab on Mobile Platforms: Several RAL systems have tried and tested experiments from Mobile Devices [44] like smartphones. Mobile Devices pose a problem of being too compact and short on resources like internet speed and computational power. So it is difficult to recreate the same effects as that of a PC. Several technologies like SMS, HTML5, Java and Adobe Flash have been used to implement different prototype of experiments, but this method of distribution is still not very popular and majority of experiments are done through the PCs.

vii. Pedagogy: RALs has been traditionally seen as replicas of on-site laboratories and every effort has been made to make these activites look exactly like traditional laboratory experiments. Some RAL accurately replicate the actual instrument panels on the web pages [40] while others use simplified interfaces and in some cases an enhanced version of the experiemtn for e.g. in a $3 \mathrm{D}$ experiemnt interface that shows the experiment action with additional simulated elements (the magnetic fields) otherwise not possible in real laboratories [39] as a form of augmented laboratory reality. However, as mentioned in [4], "It's probably a safe bet that few, if any, engineering programs implement remote labs for pedagogical reasons..." RAL usually do not carry any additional pedagogical values. iLab and Labshare developers have studied the factors affecting the 
convertability of laboratories and experiments to RAL $[1,45,46]$. Students learning outcomes [47-48] with RAL has also been studied and found to be adequate.

\section{Common Advantages of Centralized RAL Systems}

All traditional RAL systems have been successful in their truest objectives of providing access to resources along with additional services. The advantages of all these systems are:

$i$. The experiments are designed keeping a particular course and curriculum in mind. In other words, the lists of experiments are equivalent to that of an onsite laboratory. Since they are hosted by universities, there are qualified personnel to maintain update, modify or add new experiments.

ii. All of the leading RLMSs have been used for teaching at in several courses. Each one has been used by more than thousand students over several years. This suggests that these laboratories have been successful in providing an alternative platform $[3-4,45]$.

iii. Centralized RLMSs have good technical support and are available as and when needed.

\section{CHARACTERICTICS OF RLMS AND THEIR SUITABILTY FOR STEM}

While several developers have improved and worked on different aspects of the RALs such as user interface and experiment pedagogy, the core architecture has remained the same. Some of the similarities can be summarized as follows:

$i$. The current trends for developing RALs allow only experienced and expert developers to create an experiment. The experiment variety is hence limited and concentrated on particular fields of higher education.

ii. The instruments and devices used are mostly costly and complex to build and operate [49]. They use industrial standards such as GPIB, LXI [50] and PXI to connect the hardware to the computer servers. High performance software for engineering such as LabVIEW, VEE and MATLAB are also widely used to implement these experiment setups. Thus 'Rig Operation' remains a matter of high complexity in all RLMSs.

iii. The laboratory management systems are predominantly client-server in nature. All users need to $\log$ into a web address and provide user credentials to authorize access, select an experiment before utilising it. Any grid technology implemented is essentially limited to the server side of the architecture. The experiment configuration is also centralized and maintained under high-end laboratory conditions. All laboratories are designed to be operated for long periods and available to students all the time.

$i v$. There is very limited scope for collaboration among students in different geographic locations, and not typically available in RLMSs except for forums [7], although this issue has been given importance in some systems [40, 51-53]. There is also a trend to incorporate 3D user interfaces for collaborative learning purposes [37-39]. There have been multiple reports of 3D UI in various laboratories using different platforms, but it is not clear how many students have used these systems, although the positive effects on learning outcome have been reported [37].

$v$. The experiments are mostly concentrated on providing for engineering courses in undergraduate and graduate degrees. There appears to be little attention directed towards school level science education (STEM), which is rapidly becoming an important area for development using enquiry based learning methods.

The enquiry based learning methodology [54] in STEM requires students to analyse problems and find solutions by practical knowledge and implementation to understand the concepts. As such there can be an infinite number of different setups of rigs and devices that may be used for designing different concepts. Moreover with the school systems, it is the teachers and students who are more close to designing an experiment setup than experts who are already providing pre-setup rigs. But, with the above stated features for creating new laboratories is difficult for them.

There have been recent concerns on the slow adaption of remote laboratories with teachers [55] for their students. Faculty resistance to incorporate new technology in teaching and technical support issues have been cited as main reason behind underutilization of remote laboratory technologies. These reasons become more prominent if the rigs that are supposed to be used by teachers are actually designed by some other than themselves. Another study in Europe concludes that schools and teachers are very interested in remote laboratories, but are unsure how to integrate them into school curriculum [56]. This is mostly because they are incapable of fulfilling computational requirements in RAL implementations and the relevant pedagogical and technical concepts.

Since RALs are considered extended on-site laboratories, there curriculum and structure closely resembles the onsite laboratory. This is perfect of higher education where experiment have fixed nature and done with specific equipment and there is less room to 'play around' with the setup. On the other hand, in STEM education, while the list of objective may be static, the physical system on tends to be very flexible. The same kind of activity may be done with various setups to understand the STEM concepts behind it. These setups need to be built and used by students for effective learning.

In terms of RAL, a peer-to-peer system can address the problems of traditional RAL. Users may be both creators of experiments or share them with others and be user of other's experiments. Once individuals are enabled to develop and host an experiment it can create more flexibility on the laboratory providers' side. The students using these laboratories may collaborate with each other on running the setup thus giving the users fresh views of the same problem that may be different from their own. These way new and interesting ideas about practical learning and enquiry-based learning methodology may be implemented.

School level children are capable of participating in this kind of activity as evident from recent initiatives taken to incorporate RAL activities into schools such as the robot- 
RALly project [32]. A project with RAL at University of Southern Queensland was used to create enquiry-based learning activities and facilitated collaborative learning in the K-12 demography between elementary school children from Japan and Australia [33]. The study indicated that such technology can thrive in school environment also but will need transition from the client server to a peer to peer architecture where students can directly interact with others and their experiments.

\section{CONCLUSIONS}

RAL technologies so far have been confined to replicating the experience of on-site laboratories with great accuracy within a remote online environment to maintain equivalent learning outcomes. These laboratories consistently focus on the fields of higher education, but lack the capability of infrastructure support for STEM education and related physical activities. The resulting online learning tools mainly aim to resolve the resource constraints of universities. STEM education has other needs. Collaboration and hands-on experience of creating and running experiments are key requirements. The current features of RAL systems are complex and mark a barrier for individuals in schools with little experience in networking, computer systems and instrumentation. By using newer web technologies and the peer-to-peer access paradigm, RAL could provide much richer environments and experience for students remotely interacting with experiments and collaborating in joint activities in the context of STEM education.

\section{REFERENCES}

[1] V. J. Harward, J. A. Del Alamo, et al., "The iLab shared architecture a web services infrastructure to build communinities of Internet accessible laboratories," Proceedings of the IEEE, vol. 96, pp. 931-950, Jun 2008. http://dx.doi.org/10.1109/ JPROC.2008.921607

[2] J. Garcia-Zubia, P. Orduna, et al., "Application and User Perceptions of Using the WebLab-Deusto-PLD in Technical Education," FIE 2011.

[3] Gomes, L. and Garcia-Zubia, J., Eds., "Advances on Remote Laboratories and e-Learning Experiences", University of Deusto, 2007.

[4] Javier García Zubía and Gustavo R. Alves (eds.), "Using Remote Labs in Education", University of Deusto, Bilbao, 2011.

[5] C. Schmid, "Grid Supported Learning Environments and Collaborative Virtual Control Laboratories", PC'09 in Strbske Pleso, Slovakia, 2009.

[6] S. L. Green and N. M. Anid, "Training K-12 teachers in STEM education: A multi-disciplinary approach," in Integrated STEM Education Conference (ISEC), 2013 IEEE, 2013, pp. 1-4.

[7] D. Lowe, S. Murray, E. Lindsay, and D. K. Liu, "Evolving Remote Laboratory Architectures to Leverage Emerging Internet Technologies," IEEE Transactions on Learning Technologies, vol. 2, pp. 289-294, 2009. http://dx.doi.org/10.1109/TLT.2009.33

[8] Richter, T.; Tetour, Y.; Boehringer, D., "Library of Labs - A European Project on the Dissemination of Remote Experiments and Virtual Laboratories," IEEE ISM 2011, pp.543-548, 5-7 Dec. 2011.

[9] Y. Tetour, D. Boehringer, and T. Richter, "Integration of Virtual and Remote Experiments into Undergraduate Engineering Courses," 2011 Frontiers in Education Conference (Fie), 2011.

[10] Gomes, L.; Bogosyan, S., "Current Trends in Remote Laboratories," Industrial Electronics, IEEE Transactions on, vol. 56, no. 12, pp. 4744, 4756, Dec. 2009, http://dx.doi.org/10.1109/ TIE.2009.2033293

[11] J. L. Hardison, K. DeLong, P. H. Bailey, and V. J. Harward, "Deploying Interactive Remote Labs Using the iLab Shared
Architecture," Fie: 2008 Ieee Frontiers in Education Conference, Vols 1-3, pp. 1246-1251, 2008.

[12] A. Maiti, A. D. Maxwell and A. A. Kist, "An Overview of System Architectures for Remote Laboratories," in TALE 2013, pp. 661666, 2013.

[13] L. Divine and R. Williams, "STEM collaboration in virtual world academy," in Collaboration Technologies and Systems (CTS), 2013 International Conference on, 2013, pp. 569-575.

[14] L. D. Feisel and A. J. Rosa, "The Role of the Laboratory in Undergraduate Engineering Education," vol. 94, pp. 121-130, 2005. Journal of Engineering Education,

[15] G. V. Kondraske, et al., "Network-based infrastructure for distributed remote operations and robotics research," Robotics and Automation, IEEE Transactions on, vol. 9, pp. 702-704, 1993. http://dx.doi.org/10.1109/70.258062

[16] B. Aktan, C. A. Bohus, L. A. Crowl, and M. H. Shor, "Distance learning applied to control engineering laboratories," Education, IEEE Transactions on, vol. 39, pp. 320-326, 1996. http://dx.doi.org/10.1109/13.538754

[17] J. Ma and J. Nickerson, V., "Hands-On, Simualted and Remote Laboratories: A Comparative Literature Review," ACM Computing Surveys, vol. 38, pp. 1-24, 2006. http://dx.doi.org/10.1145/1132960.1132961

[18] A. A. Kist, A. Maxwell, and P. Gibbings, "Expanding the Concept of Remote Access Laboratories " presented at the 119th ASEE Annual Conference and Exposition, San Antonio, Texas, 2012.

[19] F. Arango, C. Chang, S. Esche, K., and C. Chassapis, "A Scenario for Collaborative Learning in Virtual Engineering Laboratories," in 37th ASEE/ISEE Frontiers in Education Conference, Milwaukee, WI, 2007, pp. F3G-7 - F3G-12.

[20] E. Taylor-Powell, L. Jones, and E. Henert, "Enhancing Program Performance with Logic Models, University of WisconsinExtension",

2003(http://www.uwex.edu/ces/pdande/evaluation/evallogicmodel .html)

[21] M. Tawfik, E. Sancristobal, S. Martin, R. Gil, G. Diaz, A. Colmenar, et al., "Virtual Instrument Systems in Reality (VISIR) for Remote Wiring and Measurement of Electronic Circuits on Breadboard," IEEE Transactions on Learning Technologies, vol. 6, pp. 60-72, 2013. http://dx.doi.org/10.1109/TLT.2012.20

[22] Butime, J.; Besiga, R.; Bwonyo, A.; Nakanwagi, V.; Togboa, T.; Katumba, A., "Design of online Digital Electronics laboratories based on the NI ELVIS II platform," Remote Engineering and Virtual Instrumentation (REV), 4-6 July 2012, http://dx.doi.org/10.1109/REV.2012.6293098

[23] Payne, L. J. and Schulz, M. F., "JAVA Implementation of the Batched iLab Shared Architecture," REV2013, Sydney, Australia, 6-8 Feb 2013.

[24] Fidalgo, A.V., Alves, G.R et. al., "Using remote labs to serve different teacher's needs A case study with VISIR and RemotElectLab," REV2012,pp.1,6, 4-6 July 2012, http://dx.doi.org/10.1109/REV.2012.6293149

[25] Alves, G.R. et. al. "Using VISIR in a large undergraduate course: Preliminary assessment results," IEEE EDUCON 2011, pp.11251132, 4-6 April 2011.

[26] M. Tawfik, E. Sancristobal, S. Martin, C. Gil, A. Pesquera, P. Losada, et al., "VISIR Deployment in Undergraduate Engineering Practices," 2011 Frontiers in Education Conference (Fie), 2011.

[27] P. Orduña and J. Garcia-Zubia, "Scheduling schemas among Internet Laboratories ecosystems", REV 2011, Brasov, Romania, July 2011.

[28] J. Garcia-Zubia, L. Rodriguez-Gil, et. al., "An Integrated Solution for Basics Digital Electronics: Boole-DEUSTO and WebLabDEUSTO", REV2013, Sydney, Australia, 6 - 8 February 2013.

[29] Rodriguez-Gil, L.; Orduna, P.; Garci'a-Zubia, J.; Lopez-de-Ipina, D., "Advanced integration of OpenLabs VISIR (Virtual Instrument Systems in Reality) with Weblab-Deusto," REV 2012, Bilbao, 4-6 July 2012.

[30] Garci'a-Zubia, J.; Irurzun, J.; et. al., "SecondLab: A remote laboratory under Second Life," Education Engineering (EDUCON), 2010 IEEE, vol., no., pp.351,356, 14-16 April 2010.

[31] A. A. Kist, P. Gibbings, A. D. Maxwell, and H. Jolly, "Supporting Remote Laboratory Activities at an Institutional Level," 
International Journal of Online Engineering (iJOE), vol. 9, p. 38, 2013. http://dx.doi.org/10.3991/ijoe.v9iS5.2772

[32] A. A. Kist, A. Maxwell, P. Gibbings, R. Fogarty, W. Midgley, and K. Noble, "Engineering for primary school children: Learning with robots in a remote access laboratory," 1st World Engineering Education Flash Week, SEFI Annual Conference (European Society for Engineering Education), 2011.

[33] A. Maxwell, R. Fogarty, P. Gibbings, K. Noble, A. A. Kist and W. Midgley, "Robot RAL-ly International - Promoting STEM in elementary school across international boundaries using remote access technology," in REV 2013, 2013, pp. 1-5.

[34] L. Bowtell, C. Moloney, A. A. Kist, V. Parker, A. Maxwell, and N. Reedy, "Using remote access laboratories in nursing education," Proceedings of the 9th International Conference on Remote Engineering and Virtual Instrumentation (REV 2012), pp. 1-7, 2012. http://dx.doi.org/10.1109/REV.2012.6293148

[35] L. A. Bowtell, C. Moloney, A. A. Kist, V. Parker, A. Maxwell, and N. Reedy, "Enhancing Nursing Education with Remote Access Laboratories," International Journal of Online Engineering (iJOE), vol. 8, 2012

[36] A. A. Kist and B. Basnet, "Providing Equivalent Learning Activities with Software-Based Remote Access Laboratories," International Journal of Online Engineering (iJOE), vol. 9, pp. pp. 14-19, 2013.

[37] R. Marcelino, J. B. Silva, V. Gruber, and M. S. Bilessimo, "3D virtual worlds using open source platform and integrated remote experimentation," in REV 2012, Bilbao, 4-6 July 2012.

[38] D. Costa, G. Alves, P. Ferreira, J. Silva, "Remote Labs Accessible through 3D environments A Case Study with Open Wonderland," in REV 2011 Proceedings, pp. 191-196.

[39] B. Scheucher, P. H. Bailey, C. Gütl, and J. V. Harward, "Collaborative Virtual 3D Environment for Internet-Accessible Physics Experiments," International Journal of Online Engineering (iJOE), vol. 5, 2009.

[40] Z. Nedic, J. Machotka, and A. Nafalski, "Remote Laboratory NetLab for Effective Interaction with Real Equipment over the Internet," Human System Interactions, Conference on, Vols 1 and 2, pp. 858-863, 2008.

[41] J. A. Asumadu, R. Tanner, J. Fitzmaurice, M. Kelly, H. Ogunleye, J. Belter, et al., "A Web-based electrical and electronics remote wiring and measurement laboratory (RwmLAB) instrument," Instrumentation and Measurement, IEEE Transactions on, vol. 54, pp. 38-44, 2005. http://dx.doi.org/10.1109/TIM.2004.834597

[42] D. A. H. Samuelsen and O. H. Graven, "Design of a general purpose platform for easy setup of low-cost remote laboratories in electronics," in Remote Engineering and Virtual Instrumentation (REV), 2013 10th International Conference on, 2013, pp. 1-6.

[43] Lowe, David, "Integrating Reservations and Queuing in Remote Laboratory Scheduling," Learning Technologies, IEEE Transactions on , vol.6, no.1, pp.73-84, First Quarter 2013, http://dx.doi.org/10.1109/TLT.2013.5

[44] P. Garaizar, M. Á. Vadillo, and D. Lopez-de-Ipina, "Benefits and Pitfalls of Using HTML5 APIs for Online Experiments and Simulations," International Journal of Online Engineering (iJOE), vol. 8, 2012.

[45] T. Kostulski and S. Murray, "Student Feedback from the First National Sharing Trial of Remote Labs in Australia," REV 2011, pp.203-211, 9, 2011.

[46] Lindsay, E.D. and Murray, S.J. and Lowe, D.B. and Tuttle, S.W., "Derivation of Suitability Metrics for Remote Access Mode Experiments", in REV 2010, Stockholm, Jun 292010.
[47] E. D. Lindsay and M. C. Good, "Effects of laboratory access modes upon learning outcomes," IEEE Transactions on Education, vol. 48, pp. 619-631, Nov 2005. http://dx.doi.org/10.1109/ TE.2005.852591

[48] Z. Nedic, J. Machotka and A. Nafalski, "Enriching student learning experiences in remote laboratories", 2nd Annual Conference on Engineering and Technology Education, pp. 9-14, January 2011

[49] C. M. Paiva, P. Nogueira, et. al., "A Flexible Online Apparatus for Projectile Launch Experiments," iJOE, vol. 9, 2013.

[50] J. García-Zubia, U. Hernandez-Jayo, et al., "LXI Technologies for Remote Labs: An Extension of the VISIR Project," iJOE, vol. 6, 2010.

[51] M. J. Callaghan, J. Harkin, M. El Gueddari, T. M. McGinnity, and L. P. Maguire, "Client-server architecture for collaborative remote experimentation," 3rd International Conference on Information Technology and Applications, Vol 2, Proceedings, pp. 125-129, 2005.

[52] D. Gillet, A. V. N. Ngoc, and Y. Rekik, "Collaborative web-based experimentation in flexible engineering education," Ieee Transactions on Education, vol. 48, pp. 696-704, Nov 2005. http://dx.doi.org/10.1109/TE.2005.852592

[53] C. Salzmann and D. Gillet, "Remote labs and social media: Agile aggregation and exploitation in higher engineering education," in EDUCON 2011 IEEE, 2011, pp. 307-311.

[54] Center for Science Mathematics and Engineering Education. Committee on Development of an Addendum to the National Science Education Standards on Scientific Inquiry., Inquiry and the National Science Education Standards : a guide for teaching and learning. Washington, D.C.: National Academy Press, 2000.

[55] S. W. Tuttle, D. B. Lowe, and B. Moulton, "A Survey of Issues and Approaches to Remote Laboratory Adoption by TeacherAcademics," 2011 Frontiers in Education Conference (Fie), 2011.

[56] O. Dziabenko and J. Garcia Zubia, "Secondary School Needs in Remote Experimentation and Instrumentation," iJOE, vol. 8, 2012.

\section{AUTHORS}

A. Maiti is with the Faculty of Health, Engineering and Sciences, University of Southern Queensland, Toowoomba 4350, QLD, Australia. (e-mail: anandamaiti@live.com).

A. D. Maxwell is with the Faculty of Health, Engineering and Sciences, University of Southern Queensland, Toowoomba 4350, QLD, Australia (e-mail: andrew.maxwell@usq.edu.au).

Alexander A. Kist is with the Faculty of Health, Engineering and Sciences, University of Southern Queensland, Toowoomba 4350, QLD, Australia (e-mail: kist@ieee.org).

This work is supported through the Australian Government's Digital Futures - Collaborative Research Networks (CRN) program. This article is an extended and modified version of a paper presented at the 2013 IEEE International Conference on Teaching, Assessment and Learning for Engineering (TALE2013), held 26-29 August 2013, Bali Dynasty Resort, Kuta, Indonesia. Submitted, September, 30, 2013. Published as resubmitted by the authors on March, 09, 2014. 